\title{
Outline Signal Teaching Method and College English Reading Teaching under the Environment of MOOC ${ }^{1}$
}

\author{
Fan Zhang \\ College of Foreign Languages, Central South University of Forestry \& Technology, Changsha \\ 410004, China \\ Grace195415@163.com
}

Key words: outline signal teaching method; MOOC; college English reading teaching

\begin{abstract}
Outline signal teaching method" was put forward by a Russian scholar ShaDa панов. It is to grasp the essence of teaching from the aspect of symbol, information and cognition, to pay more attention to the harmonious development of students' knowledge, emotion, and consciousness. It focuses on the energy and efficiency of classroom teaching, and highlights the teacher's leading position and cooperation among the teachers and students, which has rich connotation and value and is worth reviewing and reflecting. It also has certain guiding significance in today's popular MOOC teaching design.
\end{abstract}

\section{Introduction}

At present, the inefficient problems of college English reading teaching are embodied in that students spend long time on foreign language learning but unrewarding. Therefore to improve foreign language teaching methods and improve the efficiency of foreign language teaching is not only the general problems of teaching, but is related to the whole strategy of China's higher education quality problem (Yang Zhiqing, 2003).

The rapid development of modern brain science and computer science and technology will promote the deepening of research on foreign language teaching. It deepens the understanding of the brain cognitive mechanism and the mechanisms for language learning. The computer owns a powerful data processing and computation ability, enabling us to track, record, optimize learners' learning process, making it possible to individualize intelligent learning. It provides the institute of foreign language teaching with more advanced tools. Online technology is a kind of advanced foreign language teaching method that researchers increasingly pay attention to. We can undertake large-scale data acquisition, with the help of computer, and also can control experiment, and so on. It not only greatly reduces the labor intensity of the study, but also improves the study efficiency and precision, making the quantitative research method widely applied into foreign language teaching research. The information technology revolution represented by MOOC (Massive Open Online Course) appeared and is now causing a thorough revolution at the university.

In this environment, under the MOOC era of opportunity, the outline signal method combined with a college English reading teaching to improve students' reading ability of autonomic learning has great necessity and important significance.

\section{Theoretical basis}

"Outline signal teaching method" was proposed by a Russian scholar, ShaDa панов. It was proposed under the time background of focusing on intellectual education but guarding against "knowledge" malpractice. ShaDa thought, the world is full of "Outline Signals", each signal in the brain cortex causing "tight association reaction". In order to effectively promote the "tight

\footnotetext{
${ }^{1}$ A Project Supported by Scientific Research Fund of Hunan Provincial Education Department (No.16C1684).
} 
association reaction", teaching contents should be presented to students in appropriate symbol forms. The symbolic form are "outline signals", including all kinds of symbols or logos such as letters, words, figures, charts, etc. that can stimulate the human senses to transfer to the cerebral cortex. This kind of teaching method reflects the concept of concentrating on the main points, grasping concise information and focusing on thinking checkmarks. "Outline signal method" is to pass knowledge in the form of signals to the students.

ShaDa points out that these "outline signals" do not belong to a study outline, but a set of key words, symbols or other signals for students to think about. Outline signals are likely to make students to compress or expand the texts tries, and every student can do the job by himself. It can help students abandon stupid methods, so that the students can not only grasp the ideas when teachers narrate carefully and at the same time they have been able to follow the teacher's ideas like going through the twists and turns of the labyrinth. Therefore, ShaDa says, this kind of teaching method is a powerful weapon of psychology and pedagogy with potential and inexhaustible strength.

Outline signal teaching method grasps the essence of teaching and attaches great importance to the students' cognition, emotion, and harmonious mental development. It focuses on the vitality and efficiency of classroom teaching; and it concentrates on the teacher's dominant position and the "cooperation" between teachers and students, which are consistent with the aim of the MOOC. MOOC takes the students' "learning" as the value orientation of teaching. The key is to organize students to carry on the discussion, inspire thinking, answering questions, better realize the internalization of knowledge, and improve students' ability and quality. There are fewer researches on which outline signal teaching method is applied into college English reading teaching under the MOOC environment. MOOC has important guiding significance to the teaching design.

\section{The application of Outline signal method in college English reading teaching}

How to apply outline signal method into college English reading teaching under the MOOC environment? Now the author takes the textbook New Horizon English (second edition) (foreign language teaching and research press, 2011) as an example, using an outline signal teaching method here, to stimulate students' interest and improve the teaching quality.

3.1 outline signal method attaches great importance to the correlation between the parts and to the overall understanding.

Take the text "A Test of True Love" in the fourth unit as an example as follows:

Table 1

\begin{tabular}{|l|l|l|}
\hline Part & Answers & Questions \\
\hline 1 & Para. 1 & $\begin{array}{l}\text { Who was that woman? } \\
\text { What had happened between the two? }\end{array}$ \\
\hline 2 & Paras.2 3 & What had happened after they fell in love? \\
\hline 3 & Para.4 & Did they meet as planned? \\
\hline 4 & Paras.5 7 & Was the young woman the very one? \\
\hline 5 & Paras.8 9 & How did the woman look? \\
\hline 6 & Para.10 & What was he thinking then before the old lady? \\
\hline 7 & Para.11 & What did the man do? \\
\hline 8 & Paras.12 13 & $\begin{array}{l}\text { What was the result? } \\
\text { What did the old woman say? }\end{array}$ \\
\hline 9 & Para.14 & \\
\hline
\end{tabular}

Outline signal method pays special attention to the correlation between different kinds of information, and then grasp the theme of the whole passage. We can let the student get an answer in 
turn from the main idea of each paragraph through the above form, and then they can know how the paragraphs are linked together and how this article is smoothly produced by answering the questions. So teachers just guide and encourage students themselves to find the answer, grasp the logic relation of each part, clarify the article's ideas from the whole, comb the venation of the article, so as to cultivate students' logical thinking.

And another example is given. According to the five subtitles of text A "Five Famous Symbols of American Culture" in unit 4 in New Horizon College English Book 3 (second edition) (foreign language teaching and research press, 2011), five symbols of American culture are illustrated:

The Statute of Liberty

American Gothic

Barbie dolls

The Buffalo nickel

Uncle Sam

According to the five subheadings, students can find out the emergence of the time, origin, history and other information of every culture symbol. Teachers can ask the students to form study groups to find out important information from the Internet, make their own PPT or micro video sharing in class. These ways can deepen students' impression, cultivate their ability, and are good to promote effective integration between traditional classroom and online education. Teachers arrange 10-20- minute-long video for the students. If they have any problems, students can choose playback or fast forward, can completely decide their own learning progress. In addition to the video interpretation, intermediate quizzes are set as well. Therefore, characteristics and advantages of MOOC teaching design are fully displayed.

3.2 an outline signal method can form the image schema

In the following text of "A Test of True Love", the author describes the appearance of the girl and a woman of 40s. We can use two charts to compare them, ask the students to find out their features and then repeat.

Table 2.

\begin{tabular}{|l|l|l|l|l|}
\hline Figure & long \& thin & & Figure & more than fat \\
\hline Hair & golden \& in curls & & Hair & gray \\
\cline { 1 - 1 } \cline { 4 - 4 } Eyes & blue flowers & Eyes & fossil; gray \\
\hline Lips & a gentle firmness & Face & pale, fat \\
\cline { 1 - 1 } Suit & green & Suit & brown \\
\hline
\end{tabular}

Through description and retelling, students formed the imagery in their mind; the understanding and memory of the text are deepened. Image can make the students to have an emotional reaction and deepen their understanding. In image system, the emotional reaction is extremely important. In the process of reading comprehension, teachers should guide students to pay attention to their own emotional reactions, in order to firmly input information and get more thorough understanding about what they read (Zhang Fan, 2012).

3.3 Outline signal method can help get clear details to understand the text

Take the text "A Busy Weekday Morning" in New Horizon College English as an example. We can see a lot of time deixis in this article. Such as:

It was 6:15 A.M.

After her shower,

As she ran to catch the school bus,

After Sandy had left for school

As Jane Finch drove to work, ... 
These are important clues about the development of events. Teachers inspire students to find out the time deixis in the text step by step according to the development of the event; students can effectively understand the details and hierarchy of the text according to the time markers, then can effectively simplify the article. So this method can help students better understand the text. This shows the outline signal method is a practical and efficient teaching method.

\section{Summary}

In the teaching process, teachers provide information for students mainly by tables, graphs, figures, micro video by using outline signal method. In the form of teaching, students are guided as the main body of learning and development. In the classroom, after class and in spare time, students' cognitive development and emotion are cultivated. Teachers care about students' growth and development and establish a harmonious relationship between teachers and students. "Outline signal teaching method" fully respects the students' personality, creativity, initiative and self-regulation ability. Therefore applying outline signal method to college English reading teaching under the MOOC environment can greatly improve the efficiency and is worth to promotion.

\section{References}

[1] Sadoski, M., Paivio, A.,\&Goetz, E. T. (1991). A Critique of Schema Theory in Reading and a Dual Coding Alternative [J].Reading Research Quar-terly, 26:463-484.

[2] b. Ф. Them Wang Penggeng, Fang Li. (1984). How do the three points disappear? [M]. Beijing: Beijing normal university press.

[3] Yang Zhiqing \& Zhang Fan. (2009).A Systematic Study of Foreign Language Efficiency [J]. Journal of foreign languages in China, 1.

[4] Zhang Fan. (2012). A Study of Foreign Language Reading Efficiency Based on Metaphor and Affective Effect in DCT, Journal of Inner Mongolia University for Nationalities, 12. 